\title{
Hypertension control and care at Mulago Hospital ambulatory clinic, Kampala-Uganda
}

\author{
Isaac Ssinabulya ${ }^{1 *}$, Yvonne Nabunnya $^{1}$, Brian Kiggundu' ${ }^{1}$, Charles Musoke ${ }^{2}$, Michael Mungoma ${ }^{2}$ \\ and James Kayima ${ }^{1}$
}

\begin{abstract}
Background: Hypertension is as prevalent in many developing countries, as in the developed world and is the leading cause of cardiovascular morbidity and mortality in Africa. The control of hypertension in this resource limited setting is inadequate, a situation that translates into poorer outcomes in form of increasing incidences of stroke, heart failure, kidney failure and therefore early cardiovascular death.
\end{abstract}

Methods: This was a chart review of all the patients seen during the months of September 2012 to February 2013. We determined the level of blood pressure control, basic investigations documented as well as the choice of hypertensive treatment among patients attending a hypertension clinic in a national referral hospital, Mulago.

Results: Of the 741 patients whose charts were reviewed the median age was 60 years, Inter quartile range (IQR) was 51-71. Six hundred forty-two (86.6\%) were females. Blood pressure (BP) control defined as BP lowering to at least 140/90 was seen in only 198 (26.7\%) patients. Biophysical measurement documentation was very low especially for waist and hip circumference at $0.3 \%$. Majority of patients, 476 (64.2\%) had at least one documented investigation for the complications of hypertension. Only 103 (13.9\%) had all investigations documented in their charts. The investigations included; complete blood count (CBC), urinalysis, renal function tests (RFTs), Chest X-Ray (CXR), echocardiography (Echo) and electrocardiography (ECG). The commonly documented investigations were RFTs (45.5\%), ECG (45.2\%) and Echo (44.2\%). The commonly prescribed anti hypertensive medications were; Angiotensin receptor blockers (ARBs)/Angiotensin converting enzyme inhibitors (ACEI) (72.74\%), calcium channel blockers (72.3\%) and thiazide diuretics (68.6\%). Majority of patients were receiving three anti hypertensive medications 313 (42.2\%), with 149 (43.6\%) of these, on an ACEI/ARB, a calcium channel blocker and a thiazide diuretic.

Conclusion: Blood pressure control is suboptimal in a tertiary clinic setting at Mulago hospital and documentation of investigations is inadequate. ARB/ACEl, Calcium channel blockers and thiazide diuretics were the commonly prescribed anti hypertensive medications. There is a great need to investigate for renal and cardiac complications as well as exploring reasons for inadequate blood pressure control and consider appropriate interventions to avert bad outcomes.

Keywords: Hypertension, Blood pressure control, Management, Tertiary clinic

\section{Background}

Hypertension affects about one billion people and is estimated to cause $4.5 \%$ of current global disease burden $[1,2]$.

\footnotetext{
*Correspondence: ssinabulyaisaac@gmail.com

1 Makerere University College of Health Sciences, Kampala, Uganda Full list of author information is available at the end of the article
}

There is a strong relationship between blood pressure control and cardiovascular mortality and morbidity [3]. Hypertension is the leading cause of cardiovascular morbidity and mortality in Africa where it affects young and active adults $[4,5]$. The control of hypertension in this resource limited setting is likely to be inadequate, a situation that translates into poorer outcomes in the form of 
increasing incidences of stroke, heart failure, kidney failure and therefore cardiovascular death [6-8].

There is evidence that the diagnosis and control of hypertension is crucial in decreasing disability and mortality [9]. A meta analysis done by Lewington et al. demonstrated that BP reduction of 20/10 is associated with more than a twofold reduction in stroke death rate, and with twofold differences in the death rates from ischemic heart disease and from other vascular causes. [10].

Blood pressure elevation is usually a multifactorial condition, and therefore it is almost impossible to normalize pressure by targeting only one mechanism. In addition, drug therapy directed at any one component routinely evokes counter regulatory responses that reduce the magnitude of response. Clinical trials have documented that achieving BP targets is usually not possible with a single agent. In the Antihypertensive and Lipid-Lowering Treatment to Prevent Heart Attack Trial [11], only 26\% of patients achieved goal BP with monotherapy. In contrast, combined therapy has been shown to improve control of blood pressure in an increased number of patients [12]. In addition to the improved efficacy of combination therapy, this strategy may have fewer side effects.

Blood pressure targets and choice of drugs are dependent on co-morbidity or presence of any target organ damage and so in the routine screening for patients with hypertension it is pertinent that some tests are done $[13,14]$.

There has been documented poor BP control among community studies [15]. However there have not been many studies that have evaluated clinic blood pressure control [16]. The utility of studying clinic based control lies in having the opportunity to work up patients for secondary causes and plan interventions.

In an attempt to improve patient care in our hypertension clinics, we determined the level of blood pressure control, basic investigations documented and the choice of hypertensive treatment among patients attending the tertiary hypertension clinic Mulago national referral hospital.

\section{Methods}

\section{Study design and setting}

This was a chart review of all the patients seen through the months of September 2012 to February 2013.

The study was conducted at the hypertension clinic in the medical out patients' department of Mulago National referral hospital. The hospital is located in Uganda's capital-Kampala and doubles as the teaching hospital for Makerere University College of health sciences. This clinic runs every Monday except on public holidays. The clinic is run by physicians, medical doctors and nurses plus support from the laboratory and pharmacy. About 80-100 patients are reviewed on a given clinic day.

\section{Data collection}

We used the records book at the hypertension clinic to get a list of all the patients that attended the clinic through the months of September 2012 to February 2013, their files were retrieved and data was abstracted using a pretested tool. The team that collected data was trained before data was abstracted. The data abstraction form was piloted and adjusted to get the required information. The data collected included: socio-demographics [patient sex, and age], co-morbidities including diabetes mellitus, obesity, chronic kidney disease, stroke and clinical characteristics such as blood pressure, weight, height, and waist-hip circumference.

The investigations included: Renal function tests (RFTs), electrolytes, urinalysis, echocardiography, electrocardiogram (ECG) and Chest X-ray.

We also obtained information on the type of drugs prescribed to the patient.

\section{Operational definitions}

An individual was classified to have sub-optimal pressure control if his/her blood pressure measurement was $\geq 140 / 90 \mathrm{mmHg}$ on the last clinic visit. A missed appointment was defined as coming back to the clinic more than one week after a scheduled appointment.

\section{Data analysis}

Data were collected manually and captured into Epi-data before it was transferred to STATA version 12 for analysis. Categorical variable are expressed as percentages and continuous data as median with their corresponding inter quartile range. Logistic regression was done to determine factors associated with blood pressure control. Statistical significance was set at $\mathrm{p}<0.05$.

\section{Ethical consideration}

This research project was approved by the research and ethics committee of Mulago national referral hospital.

\section{Results}

Of the 741 charts reviewed; 642 (86.6\%) belonged to female subjects; the median age was 60 years Inter quartile range IQR (51-71). More than two-thirds 548 (74\%) of patients were 50 years and above.

\section{Blood pressure less than $140 / 90 \mathrm{mmHg}$}

Blood pressure control as defined as at least $140 / 90$ was seen in only 198 (26.7\%) of the patients whose charts were reviewed. Blood pressure control was better among female patients. Age was comparable among patients with good blood pressure control and those not controlled (Table 3). 


\section{Co-morbidity}

Ninety patients (12.2\%) had documented co-morbid conditions. Stroke was in 14 (1.9\%), Human immunodeficiency virus (HIV) infection was documented among 17 (2.3\%), diabetes $11(1.5 \%)$, asthma $11(1.5 \%)$, arthritis 8 (1.1\%), dyslipidemia $4(0.5 \%)$ and benign prostatic hypertrophy in $4(0.5 \%)$. Other conditions documented at very low frequency were renal disease, deep venous thrombosis, obstructive pulmonary disease, hyperthyroidism and peptic ulcer disease.

\section{Biophysical measurement}

The proportion of patients with biophysical measurement was very low especially for waist-hip circumference (Table 1). Weight was documented among 266 (34\%) patients, height in 169 (22.5\%) patients, while waist-hip circumference were documented among $(0.3 \%)$ patients whose charts were reviewed.

\section{Documented investigations}

While the majority of patients had at least one documented investigation 476 (64.2\%), only 103 (13.9\%) had all the expected investigations documented in their charts. The expected investigations included $\mathrm{CBC}$, urinalysis, renal function test, chest $\mathrm{X}$-ray, echocardiogram and electrocardiography. The commonly documented investigations included RFTs (45.5\%), ECG (45.2\%) and Echo (44.2\%) (Table 1).

\section{Medication}

Several classes of anti hypertensive medications were used (Table 1 ). The most commonly prescribed medications were angiotensin receptor blockers (ARBs)/angiotensin converting enzyme inhibitors (ACEI) (72.74\%), calcium channel blockers (72.3\%), thiazide diuretics (68.6\%) and beta blockers (52.2\%). The least prescribed drugs were the centrally acting vasodilators and potassium sparing diuretics which were prescribed among 4.9 and $3.2 \%$ respectively. The use of a beta blocker, ACEi, calcium channel blocker or a thiazide was associated with poor blood pressure control (Table 3).

Majority of patients were receiving three anti hypertensive medications 313 (42.2\%), with 149 (47.6\%) of these on an ACEI/ARB, a calcium channel blocker and a thiazide (Table 2).

Blood pressure control varied across number of antihypertensive drugs used and was worse among patients taking 3 and 4 drugs; odds ratio ( $95 \%$ confidence interval) $0.32(0.16-0.62)$ and $0.17(0.08-0.37)$ respectively compared to monotherapy (Table 3 ).

Other medications used included cardiac aspirin (23.4\%), lipid lowering drugs (2.8\%) and furosemide (5.3\%).
Table 1 Patient characteristics

\begin{tabular}{|c|c|c|c|}
\hline Variable & Female $\mathrm{n}(\%)$ & Male n (\%) & Total n (\%) \\
\hline \multicolumn{4}{|l|}{ Age categories (years) } \\
\hline$<40$ & $36(5.8)$ & $5(5.2)$ & $41(5.7)$ \\
\hline $40-49$ & $111(17.9)$ & 15 (15.6) & $126(17.6)$ \\
\hline $50-59$ & $172(27.8)$ & $20(20.8)$ & $192(26.9)$ \\
\hline $60-69$ & $141(22.8)$ & $18(18.7)$ & $159(22.2)$ \\
\hline $70-79$ & $121(19.6)$ & $25(26.0)$ & $146(20.4)$ \\
\hline 80 and above & $38(6.1)$ & $13(13.5)$ & $51(7.1)$ \\
\hline \multicolumn{4}{|l|}{ Biophysical measurements done } \\
\hline Weight & $234(36.5)$ & $30(30.3)$ & $264(35.6)$ \\
\hline Height & $148(22.7)$ & $20(20.2)$ & $168(22.7)$ \\
\hline WHR & $2(0.3)$ & 0 & $2(0.3)$ \\
\hline \multicolumn{4}{|l|}{ Investigations done } \\
\hline Complete blood count & $231(36.0)$ & $35(35.4)$ & $266(35.9)$ \\
\hline Urinalysis & 209 (32.6) & $34(34.3)$ & $243(32.8)$ \\
\hline Renal function tests & $292(45.5)$ & $47(47.5)$ & $339(45.8)$ \\
\hline Chest X-ray & $114(17.8)$ & $18(18.2)$ & $132(17.8)$ \\
\hline Echo & $284(44.2)$ & $48(48.5)$ & $332(44.8)$ \\
\hline ECG & $290(45.2)$ & $51(51.5)$ & $341(46.0)$ \\
\hline \multicolumn{4}{|l|}{ Medication } \\
\hline ACEi or ARB & $464(72.27)$ & $75(75.76)$ & $539(72.74)$ \\
\hline Beta blocker & $345(53.7)$ & $42(42.4)$ & $387(52.2)$ \\
\hline Calcium channel blocker & $454(70.7)$ & $82(82.8)$ & $536(72.3)$ \\
\hline Thiazide diuretic & $438(68.2)$ & $70(70.7)$ & $508(68.6)$ \\
\hline Centrally acting vasodilator & $29(4.5)$ & $7(7.1)$ & $36(4.9)$ \\
\hline Potassium sparing & $21(3.3)$ & $3(3.0)$ & $24(3.2)$ \\
\hline Furosemide & $26(4.1)$ & $13(13.1)$ & $39(5.3)$ \\
\hline Co-morbidity & $23(23.3)$ & $67(10.4)$ & $90(12.2)$ \\
\hline Blood pressure control & $182(28.4)$ & $16(16.2)$ & $198(26.7)$ \\
\hline Missed appointment & $301(47.9)$ & $45(46.4)$ & $346(47.7)$ \\
\hline
\end{tabular}

ARBs Angiotensin receptor blockers, ACEi Angiotensin converting enzyme inhibitor

\section{Missed appointments}

Almost half of the patients 348 (47.7\%) did not keep their appointments. There was no difference in blood pressure control between those that kept appointments and those that did not keep appointments OR 1.03 95\% CI (0.741.43) $\mathrm{p}=0.858$.

\section{Discussion}

Hypertension contributes to a high burden of disease and increased outpatient attendance for non communicable diseases. In Uganda specifically at the national referral hospital, the hypertension clinic is one of the busiest clinics with 80-100 patients reviewed each clinic day. Management of hypertension is aimed at controlling blood pressure to avert damage to end organs and thus improve quality of life for individuals with hypertension. In this study we found blood pressure control (as defined by a 
Table 2 Type of drugs used

\begin{tabular}{|c|c|}
\hline & n (\%) \\
\hline \multicolumn{2}{|l|}{ One drug $(5.8 \% n=43)$} \\
\hline ARBs/ACEi & $10(23.3)$ \\
\hline Calcium channel blocker & $10(23.3)$ \\
\hline Diuretics & $5(11.6)$ \\
\hline Beta blocker & $15(34.9)$ \\
\hline Centrally acting vasodilator & $1(2.3)$ \\
\hline Potassium sparing diuretic & $2(4.6)$ \\
\hline \multicolumn{2}{|l|}{ Two drugs $(32.8 \% n=243)$} \\
\hline ARBs/ACEi and beta blocker & $33(13.6)$ \\
\hline ARBs/ACEi and calcium channel blocker & $66(27.2)$ \\
\hline ARBs/ACEi and thiazide diuretic & $37(15.2)$ \\
\hline Beta blocker and calcium channel blocker & $16(6.6)$ \\
\hline Beta blocker and thiazide diuretic & $37(15.2)$ \\
\hline Others & $6(2.5)$ \\
\hline \multicolumn{2}{|l|}{ Three drugs $(42.2 \% n=313)$} \\
\hline ARBs/ACEi, beta blocker and calcium channel blocker & $53(16.9)$ \\
\hline ARBs/ACEi, beta blocker and thiazide diuretic & $42(13.4)$ \\
\hline ARBs/ACEi calcium channel blocker and thiazide diuretic & $149(47.6)$ \\
\hline Beta blocker, calcium channel blocker and thiazide diuretic & $55(17.6)$ \\
\hline Others & $14(4.5)$ \\
\hline \multicolumn{2}{|l|}{ Four drugs $(16.5 n=122)$} \\
\hline $\begin{array}{l}\text { ARBs/ACEi, beta blocker, calcium channel blocker and } \\
\text { thiazide diuretic }\end{array}$ & $102(83.6)$ \\
\hline $\begin{array}{l}\text { ARBs/ACEi, calcium channel blocker thiazide diuretic and } \\
\text { centrally acting vasodilator }\end{array}$ & $6(4.9)$ \\
\hline Others & $14(11.5)$ \\
\hline \multicolumn{2}{|l|}{ Five drugs $(1.9 \% n=14)$} \\
\hline $\begin{array}{l}\text { ARBs/ACEi, beta blocker, calcium channel blocker, thiazide } \\
\text { diuretic and centrally acting vasodilator }\end{array}$ & $5(35.7)$ \\
\hline $\begin{array}{l}\text { ARBs/ACEi, beta blocker, calcium channel blocker, thiazide } \\
\text { diuretic and potassium sparing diuretic }\end{array}$ & $8(57.1)$ \\
\hline $\begin{array}{l}\text { ARBs/ACEi, beta blocker, calcium channel blocker, centrally } \\
\text { acting vasodilator and potassium sparing diuretic }\end{array}$ & $1(7.1)$ \\
\hline
\end{tabular}

$\mathrm{BP}<140 / 90 \mathrm{mmHg}$ ) at $26.7 \%$ which is inadequate in a country that has a high burden of hypertension $[17,18]$.

In this clinic, there were older people than the young, $49.7 \%$ of patients were 60 years old and above with only $5.7 \%$ below 40 years of age. This can be partly because in the young cause of hypertension is mainly renal disease (secondary hypertension) and these patients are reviewed in the renal clinic which independently runs on a different clinic day [19].

Hypertension control was comparable across age groups but this is different from what has been revealed from community studies that found better control among patients less than 50 years [20]. Borzecki et al. also found better blood pressure control among young adults but also noted that patients above 60 years were being treated less aggressively with fewer medications [21]. In our study, the number of drugs used across age groups wasn't so varied.

Our finding illustrates a poor control compared to what Musinguzi et al. found in a community study, blood pressure control among those on treatment was achieved by $52(35.9 \%)$ [17]. The possibility of white coat effect cannot be excluded, patients in the communities could be more relaxed compared to those in ambulatory clinics who might be anxious because of the long lines and long waiting times. There is also the fact that this population was highly selected and those feeling bad (symptomatic) are more likely to attend the hypertension clinic.

Documentation of biophysical measurements and investigations was exceedingly poor in this hypertension clinic (Table 1). It is not easy from this to ascertain whether this low documentation is because these parameters were not done in the first place. Documentation enables the reviewing physician to make appropriate decisions for a patient such as choice of drugs, management of side effects and co-morbidity, request additional tests as well as make appropriate referrals whenever needed. A simple measurement like weight can be crucial in monitoring patients with hypertension as this is crucial in the control and prevention of complications.

Urinalysis to check for micro-albuminuria can easily be done to screen for renal disease and plan management. Our study reveals that only a third of the patients (32.8\%) had a urinalysis done. According to a study done by Nabbaale et al. in the same settings, 39.5\% newly diagnosed hypertensive patients were found to have microalbuminuria [22]. This implies that a sizable proportion of our hypertensive patients can be reviewed for years with undetected renal disease until the disease has progressed to a level which is expensive to manage. The low documentation for biophysical measurements and investigations clearly calls for protocol guided care in our clinic setting to guide patient management.

Majority of our patients were taking more than one drug for their blood pressure control, with $42.2 \%$ taking three drugs. Despite having several patients on more than one drug we still had poor BP control in this clinic setting. According to the Eighth Joint National Committee (JNC 8) [23], the recommended first line treatment for blacks with hypertension is a thiazide diuretic or calcium channel blocker. ACEIs have been found to be less effective compared with the $\mathrm{CCB}$ in reducing $\mathrm{BP}$ in black individuals [24]. This is not necessarily the trend in our clinic, ACEI/ARBs are the most commonly prescribed drugs and whether this partly explains the lower rates of control needs further evaluation.

Black patients with hypertension and renal disease are recommended to take ACEI or ARBs according to the 
Table 3 Factors associated with blood pressure control

\begin{tabular}{|c|c|c|c|c|c|c|}
\hline Variable & Controlled blood pressure & Uncontrolled blood pressure & Odds ratio & p value & Adjusted odds ratio & p value \\
\hline Age & $61(51-71)$ & $59(50-70)$ & $1.01(1.00-1.02)$ & 0.195 & & \\
\hline Gender-female & $182(91.9)$ & $460(84.7)$ & $2.05(1.17-3.60)$ & 0.012 & $1.85(1.03-3.34)$ & 0.04 \\
\hline ARBs & $78(39.4)$ & $232(42.7)$ & $0.87(0.63-1.21)$ & 0.416 & & \\
\hline ACEi & $55(27.8)$ & $201(37.0)$ & $0.65(0.46-0.93)$ & 0.02 & $0.53(0.36-0.78)$ & 0.001 \\
\hline Beta blockers & $94(47.5)$ & $293(54.0)$ & $0.77(0.56-0.83)$ & 0.118 & $0.62(0.44-0.88)$ & 0.008 \\
\hline Calcium channel blockers & $127(64.1)$ & $409(75.3)$ & $0.58(0.41-0.83)$ & 0.003 & $0.54(0.37-0.78)$ & 0.002 \\
\hline Centrally acting & $5(2.53)$ & $31(5.71)$ & $0.43(0.16-1.12)$ & 0.083 & $0.36(0.13-0.98)$ & 0.046 \\
\hline Thiazide diuretic & $120(60.6)$ & $388(71.5)$ & $0.61(0.44-0.86)$ & 0.005 & $0.54(0.38-0.78)$ & 0.001 \\
\hline Potassium sparing & $9(4.55)$ & $15(2.76)$ & $1.67(0.72-3.89)$ & 0.23 & & \\
\hline \multicolumn{7}{|c|}{ Number of anti-hypertensive drugs } \\
\hline One & $20(10.1)$ & $22(4.1)$ & [1] & & & \\
\hline Two & $82(41.4)$ & $154(28.4)$ & $0.59(0.30-1.14)$ & 0.113 & & \\
\hline Three & $69(34.9)$ & $239(44.0)$ & $0.32(0.16-0.62)$ & 0.001 & & \\
\hline Four & $18(9.1)$ & $116(21.4)$ & $0.17(0.08-0.37)$ & $<0.001$ & & \\
\hline Five & $5(2.5)$ & $9(1.7)$ & $0.61(0.18-2.13)$ & 0.44 & & \\
\hline Having all investigations & $24(12.1)$ & $79(14.5)$ & $0.81(0.50-1.32)$ & 0.399 & & \\
\hline Having any comorbidity & $25(12.6)$ & $65(12.0)$ & $1.06(0.65-1.74)$ & 0.809 & & \\
\hline Keeping appointment & $94(48.2)$ & $252(47.5)$ & $1.03(0.74-1.43)$ & 0.858 & & \\
\hline
\end{tabular}

$A R B s$ angiotensin receptor blockers, $A C E i$ angiotensin converting enzyme inhibitor

African American Study of Kidney Disease and Hypertension (AASK) [25]. Patients with CKD and hypertension usually require more than 1 drug to achieve goal $B P$ and therefore an ACEI or ARB is used either as initial therapy or as second-line therapy in addition to a diuretic or CCB in black patients with CKD. However in our patient population little is known about CKD status and so use of ACEI or ARB is not from an informed point of view. This emphasizes the need to screen patients and also study this further in our patient population.

We found that majority of patients on monotherapy were taking beta blockers, this is not in line with the guidelines. Beta-blockers are not recommended for the initial treatment of hypertension because their use resulted in a higher rate of cardiovascular death, myocardial infarction, or stroke [26]. Beta-blockers are readily available and cheap in Uganda, this could explain their common use.

This finding of low blood pressure control prompts us to consider other modalities that can contribute to better blood pressure control. There have been studies that have shown that renal denervation may be a cost effective approach compared to medical management in management of resistant hypertension $[27,28]$. The use of renal denervation is still controversial with demonstrated no benefit from the Simplicity 3 trial [29], however some scholars believe that renal denervation done by experienced hands and good patient selection can be beneficial. We cannot conclude though that all patients that had poor control have resistant hypertension but this is an aspect that needs consideration knowing that some patients could have resistant hypertension. In Africa, as we advance in catheter based interventions by our physicians; nerve denervation could be a welcome solution among patients with resistant hypertension.

This was a retrospective chart review study; we could not ascertain why control is low however we describe the magnitude of the problem and highlight key gaps in documentation. we cannot conclude that tests were not done since we went by what was documented but this clearly demonstrate that we have room to improve and make the care for our patients better.

Evaluation for a hypertensive patient ought to be comprehensive to identify risk factors, co-morbidity as well as stratify patients to risk categories and plan appropriate treatment. In a clinic setting there is opportunity to make management of hypertension better and consequently avert the bad outcomes that are associated with poor blood pressure control.

\section{Conclusions}

Blood pressure control is suboptimal in a clinic setting at Mulago hospital and documentation of basic investigations is inadequate. ARB/ACEI, Calcium channel blockers and thiazide diuretics were the commonly prescribed anti hypertensive medications. There is an urgent need to explore reasons for suboptimal control and institute 
measures to avert cardiovascular complications that are associated with poor blood pressure control.

Evaluation for a hypertensive patient ought to be comprehensive to identify risk factors, co-morbidity as well as stratify patients to risk categories and plan appropriate treatment. Protocols have to be put in place and implemented for better patient care. In a clinic setting there is opportunity to make management of hypertension better and consequently avert the bad outcomes that are associated with poor blood pressure control.

\section{Abbreviations}

AASK: African American Study of Kidney Disease and Hypertension; ACEl: angiotensin converting enzyme inhibitors; ALLHAT: antihypertensive and lipid-lowering treatment to prevent heart attack trial; ARB: angiotensin receptor blockers; CCB: calcium channel blocker; CKD: chronic kidney disease; CXR: chest X-ray; ECG: electrocardiogram; JNC: joint national committee.
\end{abstract}

\section{Authors' contributions}

IS, YN, JK made substantial contribution to study conception and design. IS and BK analyzed data and drafted manuscript. All authors read and approved the final manuscript.

\section{Author details}

${ }^{1}$ Makerere University College of Health Sciences, Kampala, Uganda. ${ }^{2}$ Mulago National Referral Hospital, Kampala, Uganda.

\section{Acknowledgements}

The authors would like to appreciate all the staff at Mulago Hospital hypertension clinic.

\section{Competing interests}

The authors declare that they have no competing interests.

\section{Ethical approval and consent to participate}

This research project was approved by the research and ethics committee of Mulago national referral hospital. Patient consent to participate was waived because this was a chat review. Patient identifiers were all removed to maintain confidentiality.

\section{Funding}

Research reported in this publication was supported by the Fogarty International Center, the National Heart Lung and Blood Institute, and the Common Fund of the National Institutes of Health under Award Number R24 TW008861. The content is solely the responsibility of the authors and does not necessarily represent the official views of the National Institutes of Health. The funders had no role in study design, data collection and analysis, decision to publish, or preparation of the manuscript.

Received: 26 January 2016 Accepted: 13 November 2016

Published online: 17 November 2016

\section{References}

1. Kearney PM, Whelton M, Reynolds K, Muntner P, Whelton PK, et al. Global burden of hypertension: analysis of worldwide data. Lancet. 2005;365:217-23.

2. Lopez AD. Global burden of disease and risk factors. England: Oxford University Press; 2006

3. Stamler J, Stamler R, Neaton JD, Wentworth D, Daviglus ML, Garside D, Dyer AR, Liu K, Greenland P. Low risk-factor profile and long-term cardiovascular and noncardiovascular mortality and life expectancy: findings for 5 large cohorts of young adult and middle-aged men and women. JAMA. 1999;282(21):2012-8.
4. Bertrand E. Cardiovascular disease in developing countries. New York: McGraw-Hill; 1999.

5. Brundtland GH. Reducing risks to health, promoting healthy life. JAMA. 2002;288:1974-5.

6. Walker R, Whiting D, Unwin N, Mugusi F, Swai M, et al. Stroke incidence in rural and urban Tanzania: a prospective, community-based study. Lancet Neurol. 2010;9:786-92.

7. Kingue S, Dzudie A, Menanga A, Akono M, Ouankou M, et al. A new look at adult chronic heart failure in Africa in the age of the Doppler echocardiography: experience of the medicine department at Yaounde General Hospital. Ann Cardiol Angeiol (Paris). 2005;54:276-83.

8. Arogundade FA, Barsoum RS. CKD prevention in Sub-Saharan Africa: a call for governmental, nongovernmental, and community support. Am J Kidney Dis. 2008;51:515-23.

9. Fiscella K, Holt K. Racial disparity in hypertension control: tallying the death toll. Ann Fam Med. 2008;6:497-502.

10. Lewington S, Clarke R, Qizilbash N, Peto R, Collins R. Age-specific relevance of usual blood pressure to vascular mortality: a meta-analysis of individual data for one million adults in 61 prospective studies. Lancet. 2002;360:1903-13.

11. Furberg $C D$, Psaty $B M$, Pahor M, Alderman MH. Clinical implications of recent findings from the antihypertensive and lipid-lowering treatment to prevent heart attack trial (ALLHAT) and other studies of hypertension. Ann Intern Med. 2001;135:1074-8.

12. Mourad JJ, Waeber B, Zannad F, Laville M, Duru G, et al. Comparison of different therapeutic strategies in hypertension: a low-dose combination of perindopril/indapamide versus a sequential monotherapy or a stepped-care approach. J Hypertens. 2004;22:2379-86.

13. Katakam R, Brukamp K, Townsend RR. What is the proper workup of a patient with hypertension? Clevel Clin J Med. 2008;75:663-72.

14. Chobanian AV, Bakris GL, Black HR, Cushman WC, Green LA, et al. Seventh report of the joint national committee on prevention, detection, evaluation, and treatment of high blood pressure. Hypertension. 2003;42:1206-52

15. Kayima J, Wanyenze RK, Katamba A, Leontsini E, Nuwaha F. Hypertension awareness, treatment and control in Africa: a systematic review. BMC Cardiovasc Disord. 2013;13:54.

16. Batubenga MM, Omole OB, Bondo MC. Factors associated with blood pressure control among patients attending the outpatient clinic of a South African district hospital. Trop Doc. 2015;45(4):225-30.

17. Musinguzi $G$, Nuwaha F. Prevalence, awareness and control of hypertension in Uganda. PLoS ONE. 2013;8:e62236.

18. Wamala JF, Karyabakabo Z, Ndungutse D, Guwatudde D. Prevalence factors associated with hypertension in Rukungiri district, Uganda-a community-based study. Afr Health Sci. 2009;9:153-60.

19. Kalyesubula R, Lunyera J, Makanga G, Kirenga B, Amukele TK. A 4-year survey of the spectrum of renal disease at a National Referral Hospital Outpatient Clinic in Uganda. Kidney Int. 2015;87:663.

20. Agyemang C, Bruijnzeels MA, Owusu-Dabo E. Factors associated with hypertension awareness, treatment, and control in Ghana, West Africa. J Hum Hypertens. 2006;20:67-71.

21. Borzecki AM, Glickman ME, Kader B, Berlowitz DR. The effect of age on hypertension control and management. Am J Hypertens. 2006;19:520-7.

22. Nabbaale J, Kibirige D, Ssekasanvu E, Sebatta ES, Kayima J, et al. Microalbuminuria and left ventricular hypertrophy among newly diagnosed black African hypertensive patients: a cross sectional study from a tertiary hospital in Uganda. BMC Res Notes. 2015;8:198.

23. James PA, Oparil S, Carter BL, Cushman WC, Dennison-Himmelfarb C, et al. 2014 evidence-based guideline for the management of high blood pressure in adults: report from the panel members appointed to the eighth joint national committee (JNC 8). JAMA. 2014;311:507-20.

24. Leenen FH, Nwachuku CE, Black HR, Cushman WC, Davis BR, et al. Clinical events in high-risk hypertensive patients randomly assigned to calcium channel blocker versus angiotensin-converting enzyme inhibitor in the antihypertensive and lipid-lowering treatment to prevent heart attack trial. Hypertension. 2006;48:374-84.

25. Wright JT Jr, Bakris G, Greene T, Agodoa LY, Appel LJ, et al. Effect of blood pressure lowering and antihypertensive drug class on progression of hypertensive kidney disease: results from the AASK trial. JAMA. 2002;288:2421-31. 
26. Dahlof B, Devereux RB, Kjeldsen SE, Julius S, Beevers G, et al. Cardiovascular morbidity and mortality in the Losartan intervention for endpoint reduction in hypertension study (LIFE): a randomised trial against atenolol. Lancet. 2002;359:995-1003.

27. Geisler BP, Egan BM, Cohen JT, Garner AM, Akehurst RL, et al. Cost-effectiveness and clinical effectiveness of catheter-based renal denervation for resistant hypertension. J Am Coll Cardiol. 2012;60:1271-7.
28. Gladwell D, Henry T, Cook M, Akehurst R. Cost effectiveness of renal denervation therapy for the treatment of resistant hypertension in the UK. Appl Health Econ Health Policy. 2014;12:611-22.

29. Bhatt DL, Kandzari DE, O'Neill WW, D'Agostino R, Flack JM, et al. A controlled trial of renal denervation for resistant hypertension. N Engl J Med. 2014;370:1393-401.

\section{Submit your next manuscript to BioMed Central and we will help you at every step:}

- We accept pre-submission inquiries

- Our selector tool helps you to find the most relevant journal

- We provide round the clock customer support

- Convenient online submission

- Thorough peer review

- Inclusion in PubMed and all major indexing services

- Maximum visibility for your research

Submit your manuscript at

www.biomedcentral com/submit 